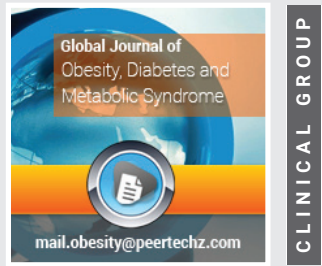

Review Article

\section{Brief Review of Newer}

\section{Antiglycemic Agents as}

\section{Options in the Treatment of Diabetic Kidney Disease}

\section{Brian K Irons ${ }^{1 *}$, Molly Minze ${ }^{2}$, Lisa Chastain ${ }^{3}$ and Michael E McMurry ${ }^{4}$}

${ }^{1}$ PharmD, Texas Tech University Health Sciences Center, Jerry H. Hodge School of Pharmacy, Lubbock Campus, USA

${ }^{2}$ PharmD, Texas Tech University Health Sciences Center, Jerry H. Hodge School of Pharmacy, Abilene Campus, USA

${ }^{3}$ Pharm D, Texas Tech University Health Sciences Center, Jerry H. Hodge School of Pharmacy- Dallas, Fort Worth Campus, USA

${ }^{4}$ DNP, Texas Tech University Health Sciences Center, Department of Internal Medicine, Nephrology Division, Lubbock Campus, USA
Received: 17 Ferbruary, 2020

Accepted: 09 May, 2020

Published: 11 May, 2020

*Corresponding author: Brian $\mathrm{K}$ Irons, PharmD, Texas Tech University Health Sciences Center, Jerry H. Hodge School of Pharmacy, Lubbock Campus, USA,

E-mail:brian.irons@ttuhsc.edu

Keywords: Diabetes; kidney disease; DPP4: Dipeptidyl peptidase 4; GLP1: Glucagon-like peptide 1, SGLT 2: Sodium glucose co-transporter 2

https://www.peertechz.com

Check for updates

\begin{abstract}
Diabetes remains the leading cause of chronic kidney disease and with its increased prevalence the risk for Diabetic Kidney Disease (DKD) continues to rise and has a significant impact on diabetes morbidity and mortality as well as health care resources. There is a clear need to clinicians and patients for new treatments to limit the burden of DKD. Three classes of non-insulin therapy for type 2 diabetes mellitus (T2DM), dipeptidyl peptidase 4 (DPP4) inhibitors, glucagon-like peptide 1 (GLP1) agonists, and sodium glucose co-transporter 2 (SGLT2) inhibitors have been evaluated in large cardiovascular safety studies in which exploratory or post-hoc analyses shed some light on renal outcomes with these agents. Smaller studies focused on efficacy and safety in patients with T2DM and diabetic kidney disease also provide some evidence of renal outcomes. As a class, both DPP4 inhibitors and GLP1 agonists show promise in reducing albuminuria but have so far not been shown to impact more robust renal outcomes such as doubling of serum creatinine or progression in renal insufficiency. More compelling data exist on the benefits of SGLT2 inhibitors. From the cardiovascular safety studies, empagliflozin, canagliflozin, and dapagliflozin have shown reductions in not just albuminuria, but also show significant reductions in progression of renal insufficiency and a small reduction in the development of end-stage renal disease. The cardiovascular safety studies, however, were not designed to specifically assess renal benefit. Canagliflozin in a landmark trial specifically designed to evaluate its use in patients with diabetes and DKD, has shown to reduce doubling of serum creatinine, progression to end-stage renal disease while also demonstrating a reduction in cardiovascular morbidity as well. It is the first agent in nearly twenty years to obtain an indication for the treatment of DKD.
\end{abstract}

\section{Abbreviations}

CKD: Chronic Kidney Disease; T2DM: Type 2 Diabetes Mellitus; US: United States; DKD: Diabetic Kidney Disease; DPP4: Dipeptidyl Peptidase 4 inhibitors, glucagon-like peptide 1 agonists; FDA: Food and Drug Administration; CVOT: Cardiovascular Outcome Trial; UACR: Urine Albumin Creatinine Ration; eGFR: estimated Glomerular Filtration Rate;
CREDENCE: Canagliflozin and Renal Events in Diabetes with Established Nephropathy Clinical Evaluation

\section{Introduction}

Diabetes continues to be the leading cause of Chronic Kidney Disease (CKD) worldwide with an estimated $40 \%$ of patients with diabetes going on to develop some degree of CKD [1]. This greatly increases the risk for end-stage renal disease 
and cardiovascular morbidity and mortality [2,3]. With the ever-increasing prevalence of diabetes, the incidence of CKD continues to rise as well. In older patients in particular, CKD rates increase with advanced age and in the United States (US) Medicare population, this increase resulted in an estimated \$39 billion in health care expenditures in $\mathbf{2 0 1 7}$ for patients with CKD and concurrent diabetes [4]. For the past two decades, leading US guidelines in the treatment of diabetes have stressed the need for improved glycemic and hypertension control as a means to limit the onset of diabetic kidney disease (DKD) or to reduce its progressive nature [5]. Despite these recommendations there remains a significant residual risk for the onset or progression of DKD. Efforts have been called for to improve overall health outcomes for patients with DKD and for the development of new therapeutic entities that can stem this tide. $[1,6]$. This review assesses the renal benefits of three classes of antidiabetic agents. This includes agents that affect the incretin system, i.e. Dipeptidyl Peptidase 4 inhibitors (DPP4i) and Glucagon-Like Peptide (GLP)-1 agonists, or affect kidney glucosuria i.e. Sodium Glucose co-Transporter 2 inhibitors (SGLT2). These three classes are highlighted due to the fact there is renal data, positive or neutral, with each agent from glycemic efficacy studies, in patients with or without existing DKD, and each agent within these classes has undergone a Food and Drug Administration (FDA)-mandated Cardiovascular Outcome Trial (CVOT). These CVOT studies are typically much larger and most included a prespecified evaluation of a composite renal outcome or post-hoc analysis of such. Lastly, one landmark study specifically designed to evaluate an agent in patients with DKD showing robust benefit in this patient population will be discussed. It is the intent of this brief review to provide the reader with synopses of each class and if or where the agents may play a role in treating DKD.

\section{Incretin agents}

\section{DPP4 inhibitors}

In studies designed to assess glycemic efficacy in patients with or without existing DKD, the DPP4i data has shown this class of agents likely has a positive effect on reducing albuminuria via changes in Urine Albumin-to-Creatinine Ratio (UACR). These trials differ in duration of therapy, extent of baseline DKD, and how changes in DKD were reported. The changes in UACR vary from baseline by $5-43 \mathrm{mg} / \mathrm{g}$ depending on study and agent evaluated [7-9]. The studies to date, however, have not shown a significant reduction in progression of more robust renal outcomes such as doubling of serum creatinine, progression to end-stage renal disease, or renal death. The CVOT studies involving the DPP4is each included a composite renal outcome. It should be noted the CVOT studies mandated by the FDA are to demonstrate cardiovascular safety compared to placebo and are not specifically designed to evaluate renal outcomes. Subjects evaluated in these studies tended to be older with established cardiovascular disease or at high risk for such and baseline renal function and degree of albuminuria varied between study. None of the studies showed a statistically significant or clinically relevant reduction in progression of renal insufficiency, need for dialysis, or renal death [10-13].
Currently, none of the agents within this class are approved for use in DKD and based on the limited data described above should not be used off-label for such.

\section{GLP1 agonists}

The data for GLP1 agonists in studies evaluating glycemic benefit in patients with T2DM with or without existing DKD show mixed results in UACR improvements or changes in renal function. Three agents within this class, liraglutide, dulaglutide, and oral semaglutide have each assessed renal outcomes in patients with T2DM and moderate renal impairment (baseline estimated glomerular filtration rate (eGFR) between 30 and 59 $\mathrm{ml} / \mathrm{min} / 1.73 \mathrm{~m}^{2}$ ). In a six-month study of over 300 patients no changes in UACR or improvement in eGFR were found in those receiving oral semaglutide compared to placebo [14]. A twelvemonth study comparing dulaglutide to insulin glargine in over 570 patients showed a modest improvement in eGFR with dulaglutide $\left(<3 \mathrm{ml} / \mathrm{min} / 1.73 \mathrm{~m}^{2}\right)$ compared to those receiving insulin therapy but failed to show a difference in UACR between the two groups [15]. Liraglutide failed to show a change in either albuminuria or change in eGFR compared to placebo in a six-month study in over 270 patients [16]. Renal outcomes in the much larger CVOT studies were evaluated for many of the agents within this class including lixisenatide, liraglutide and once-weekly formulations of semaglutide, dulaglutide, and exenatide (Table 1). Each study varied in baseline cardiovascular risk and duration of study. The average baseline renal function was greater than $70 \mathrm{ml} / \mathrm{min} / 1.73 \mathrm{~m}^{2}$ and how baseline UACR was expressed varied widely between study but most patients had normal albuminuria. Lixisenatide and oral semaglutide did not have a prespecified composite renal outcome embedded in their respective CVOT studies. However, lixisenatide showed a smaller percent change in UACR over the two-year study compared to placebo but did not show an improvement in the development of persistent macroalbuminuria $(>300 \mathrm{mg} / \mathrm{g}$ ), change in eGFR, or in doubling of serum creatinine [17]. In contrast to the CVOT studies with DPP4is, the studies with the GLP1 agonists that included a composite renal outcome each showed a significant $15-36 \%$ relative reduction though the composite outcome differed between studies (Table 1). [18-21] However, upon closer evaluation, it appears that the driving force behind the reduction in the composite outcome was change in albuminuria and no study showed an ability to slow the progression of eGFR decline or need for renal replacement therapy. Currently, none of the agents within this class are approved for use in DKD and based on the limited data described above should not be used off-label for such.

\section{SGLT2 Inhibitors}

Studies evaluating glycemic efficacy in patients with and without baseline DKD show that the SGLT2 inhibitors also improve albuminuria. Empagliflozin in patients with microalbuminuria (UACR $30-300 \mathrm{mg} / \mathrm{g}$ ) has demonstrated a $32 \%$ reduction in UACR and a $41 \%$ reduction in those with baseline macroalbuminuria ( $>300 \mathrm{mg} / \mathrm{d}$ ) [22]. Ertugliflozin has also shown a $29-33 \%$ reduction in UACR in a 24 -month study compared to subjects receiving placebo or glimepiride [23]. Canagliflozin in greater than 260 patients with stage 3 
Table 1: Renal Outcomes from Cardiovascular Outcome Trials of Injectable GLP1 agonists or Oral SGLT-2 inhibitors.

\begin{tabular}{|c|c|c|c|}
\hline Agent Evaluated & $\begin{array}{c}\text { Study Duration } \\
\text { (years) }\end{array}$ & $\begin{array}{l}\text { Number of } \\
\text { Subjects }\end{array}$ & Composite Renal Outcome \\
\hline \multicolumn{4}{|l|}{ GLP1 Agonists } \\
\hline $\begin{array}{c}\text { Lixisenatide } \\
\text { [17] }\end{array}$ & 2.1 & 6068 & NA \\
\hline $\begin{array}{l}\text { Liraglutide } \\
\text { [18] }\end{array}$ & 3.8 & 9340 & $\begin{array}{l}\text { New-onset persistent macroalbuminuria, doubling of } \\
\text { serum } \mathrm{Cr} \text { and eGFR }<45 \mathrm{ml} / \mathrm{min} / 1.73 \mathrm{~m} 2 \text {, need for renal } \\
\text { replacement, or renal death } \\
15.0 \text { Liraglutide vs } 19.0 \text { Placebo (rate per } 1000 \text { patient } \\
\text { years of observation), } 22 \% \text { relative reduction }(p=0.003 \text { ) }\end{array}$ \\
\hline $\begin{array}{c}\text { Semaglutide } \\
\text { (once weekly } \\
\text { subcutaneous) } \\
\text { [19] }\end{array}$ & 2.1 & 3297 & $\begin{array}{l}\text { New or worsening nephropathy (macroalbuminuria, } \\
\text { doubling of serum } \mathrm{Cr} \text { and } \mathrm{CrCl}<45 \mathrm{ml} / \mathrm{min} / 1.73 \mathrm{~m}^{2} \text {, or } \\
\text { need for renal replacement therapy) }\end{array}$ \\
\hline
\end{tabular}

Individual Renal Outcomes

$\%$ change in UACR

$+24 \%$ Lixisenatide vs $+34 \%$ Placebo $(p=0.004)$

Baseline UACR $<300$ to $\geq 300 \mathrm{mg} / \mathrm{g}$

$6.5 \%$ Lixisenatide vs $7.7 \%$ Placebo (NS)

Doubling of serum creatinine

$1 \%$ Lixisenatide vs $1 \%$ Placebo (NS)

Development of ESRD: $<1 \%$ in each group (NS)

Rate per 1000 patient years of observation

Persistent macroalbuminuria

9.0 Liraglutide vs 12.1 Placebo, $26 \%$ relative reduction $(p=0.004)$

Doubling of serum $\mathrm{Cr}$ and persistent eGFR $<45 \mathrm{ml} / \mathrm{min} / 1.73 \mathrm{~m}^{2}$ 4.9 Liraglutide vs 5.5 Placebo (NS)

Need for renal replacement therapy

3.1 Liraglutide vs 3.6 Placebo (NS)

Renal death

0.4 Liraglutide vs 0.3 Placebo (NS)

Persistent macroalbuminuria

$2.7 \%$ Semaglutide vs $4.9 \%$ Placebo, $46 \%$ relative reduction $(p=0.001)$

Doubling of serum $\mathrm{Cr}$ and persistent $\mathrm{CrCL}<45 \mathrm{ml} / \mathrm{min} / 1.73 \mathrm{~m}^{2}$ $1.1 \%$ Semaglutide vs $0.8 \%$ Placebo (NS)

Need for renal replacement therapy $0.7 \%$ Semaglutide vs $0.7 \%$ Placebo (NS)

New macroalbuminuria

$2.2 \%$ Exenatide vs $2.5 \%$ (NS)

Mean change in eGFR

$0.21 \mathrm{ml} / \mathrm{min} / 1.73 \mathrm{~m}^{2}$ (NS)

Composite 2: Composite 1 plus incident macroalbuminuria

$5.8 \%$ Exenatide vs $6.5 \%$ Placebo, $15 \%$ relative reduction $(p=0.03)$

9901 New macroalbuminuria, sustained decline in eGFR $\geq 30 \%$ from baseline, or need for renal replacement

$17.1 \%$ Dulaglutide vs $19.6 \%$ Placebo, $15 \%$ relative reduction $(p=0.0004)$

New macroalbuminuria

$8.9 \%$ Dulaglutide vs $11.3 \%$ Placebo, $23 \%$ relative reduction $(p<0.0001)$

Sustained decline in eGFR $\geq 30 \%$ 9.2\% Dulaglutide vs $10.1 \%$ Placebo (NS)

Need for renal replacement $0.3 \%$ Dulaglutide vs $0.4 \%$ Placebo (NS)

Progression to UACR $>300 \mathrm{mg} / \mathrm{g}$

Progression to UACR $>300 \mathrm{mg} / \mathrm{g}$, doubling of serum $\mathrm{C}$ and decline in eGFR $\leq 45 \mathrm{ml} / \mathrm{min} / 1.73 \mathrm{~m}^{2}$, initiation of renal $11.2 \%$ Empagliflozin vs $16.2 \%$ Placebo, $38 \%$ relative reduction replacement, or renal death $(p<0.001)$

$12.7 \%$ Empagliflozin vs $18.8 \%$ Placebo, $39 \%$ relative reduction $(p<0.001)$
Doubling of serum $\mathrm{Cr}$ and decline in eGFR $\leq 45 \mathrm{ml} / \mathrm{min} / 1.73 \mathrm{~m}^{2}$ $1.5 \%$ Empagliflozin vs $2.6 \%$ Placebo, $44 \%$ relative reduction $(p<0.001)$

Initiation of renal replacement therapy

$0.3 \%$ Empagliflozin vs $0.6 \%$ Placebo, $55 \%$ relative reduction $(p=0.04)$

Citation: Irons BK, Minze M, Chastain L, McMurry ME (2020) Brief Review of Newer Antiglycemic Agents as Options in the Treatment of Diabetic Kidney Disease. Glob $\mathrm{J}$ Obes Diabetes Metab Syndr 7(2): 012-017. DOI: https://dx.doi.org/10.17352/2455-8583.000041 


Canagliflozin

$[27,28]$

3.6

10142

\section{$40 \%$} $40 \%$ reduction in eGFR, renal replacement initiation, or
renal death

5.5 Canagliflozin vs 9.0 Placebo (rate per 1000 patient years), $40 \%$ relative reduction ( $p$ values not provided)

Dapagliflozin 4.2 17160 [29]

\begin{abstract}
Sustained decrease of $40 \%$ or greater in eGFR and $<60$ $\mathrm{ml} / \mathrm{min} / 1.73 \mathrm{~m}^{2}$, new end-stage renal disease, or death due to cardiovascular or renal cause
\end{abstract}

4.3 Dapagliflozin vs 5.6 Placebo (rate per 1000 patient years), $24 \%$ relative reduction ( $p$ value not provided, $95 \% \mathrm{Cl}$ not including 1 ) Rate per 1000 patient years ( $p$ values not reported but $95 \% \mathrm{Cl}$
did not include 1)

Progression of albuminuria

89 Canagliflozin vs 128 Placebo, $27 \%$ relative reduction

$40 \%$ reduction in eGFR

5.3 Canagliflozin vs 8.7 Placebo, $40 \%$ relative reduction

Doubling of serum creatinine

1.2 Canagliflozin vs 2.4 Placebo, $50 \%$ relative reduction

( $p$ values not reported and/or $95 \% \mathrm{Cl}$ did not include 1 for relative reductions)

Sustained decrease of $40 \%$ or greater in eGFR and $<60 \mathrm{ml} /$ $\mathrm{min} / 1.73 \mathrm{~m}^{2}$, new end-stage renal disease, or death due to renal cause

1.5 Dapagliflozin vs 2.8 Placebo, (rate per 1000 patient years), $47 \%$ relative reduction

$$
\begin{gathered}
\text { Sustained } 40+\% \text { decrease in eGFR and eGFR }<60 \mathrm{ml} / \\
\min / 1.73 \mathrm{~m}^{2}
\end{gathered}
$$

End-stage renal disease

$0.1 \%$ Dapagliflozin vs $0.2 \%$ Placebo, $69 \%$ relative reduction GLP: Glucagon-Like Peptide; SGLT: Sodium Glucose co-Transporter; NA: Not Available or Not Assessed; UACR: Urine Albumin; creatinine ratio; NS: Not Significant; ESRD: End-Stage Renal Disease; Cr: Creatinine; eGFR: estimated Glomerular Filtration Rate; CrCl: Creatinine clearance, Cl: Confidence Interval

CKD demonstrated a $21-30 \%$ reduction in UACR compared to placebo in a six-month study [24]. Lastly, dapagliflozin in 166 patients with diabetes, DKD, and baseline microalbuminuria showed a 44-57\% reduction in UACR compared to placebo [25]. The argument for use of this class of agent to stem progression of DKD gets more compelling upon assessment of composite renal outcomes from the three published CVOT studies involving empagliflozin, canagliflozin, and dapagliflozin [2629]. (Table 1) As in the CVOT studies involving GLP1 agonists, in the SGLT2 inhibitor CVOT studies the majority of patients had normal baseline albuminuria and renal function and the studies varied in duration, size, and baseline cardiovascular risk. A $24 \%-40 \%$ relative reduction in the composite renal outcomes were found in these three studies and in the case of both canagliflozin and dapagliflozin the composite outcome did not include changes in UACR suggesting albuminuria is not the driving force in these outcomes [26-29]. Each study when looking at changes in renal function showed a significant reduction in slowing decline in eGFR and in the case of both empagliflozin and dapagliflozin these two studies found a significant, albeit small, reduction in those requiring renal replacement therapy or progressing to end-stage renal disease. Despite the CVOT studies not being specifically designed to show renal benefit, each showed more robust renal outcomes than the other two classes discussed above.

In 2019, the landmark Canagliflozin and Renal Events in Diabetes with Established Nephropathy Clinical Evaluation (CREDENCE) study was published and to date serves as the most compelling evidence in improving renal outcomes with a SLGT2 inhibitor in patients with T2DM and DKD [30]. The 2.6-year study evaluated low dose (100 mg daily) canagliflozin compared to placebo in patients with diabetes whose baseline
eGFR was between $30-89 \mathrm{ml} / \mathrm{min} / 1.73 \mathrm{~m}^{2}$ (mean 56) and UACR between $300-5000 \mathrm{mg} / \mathrm{g}$ (mean 927). The study found a $30 \%$ relative reduction in the primary renal outcome (defined as need for dialysis, renal transplantation, sustained eGFR <15 $\mathrm{ml} / \mathrm{min} / 1.73 \mathrm{~m}^{2}$, doubling of serum creatinine, or death from renal or cardiovascular disease). Components of the primary outcome assessed separately showed significant reductions in progression to end-stage renal disease, a doubling of serum creatinine, and reductions in cardiovascular events and heart failure admissions. The specific mechanisms of how these agents improve renal outcomes is not fully understood but is likely multifactorial and can't be explained by mild improvements in glycemic $(-0.11 \%)$ or systolic blood pressure $(-2.4 \mathrm{~mm} \mathrm{Hg})$ control seen in the CREDENCE study $[30,31]$. Canagliflozin now has a new indication from the FDA to reduce DKD in patients with T2DM, the first such indication for an agent in nearly 20 years. In addition to standards of care to improve glycemic, blood pressure control, and use of agents to block the renin angiotensin system, canagliflozin should be considered in patients who have similar baseline DKD as in the CREDENCE study.

\section{Conclusions}

While patients receiving a DPP4i or GLP1 agonist may experience improvements in albuminuria, there is little data to support their use to slow the progression of DKD in terms of more robust renal outcomes that show a slowing of disease progression related to renal function or need for renal replacement therapy. The SGLT2 inhibitors, on the other hand, in their CVOT studies and canagliflozin in the CREDENCE study show this class of agents does influence these types of renal outcomes. Whether the results found in CREDENCE 
will also hold true for the other agents in this class remains to be determined but both dapagliflozin and empagliflozin have ongoing studies evaluating this concept. New research opportunities exist to assess if SGLT2 inhibitors have a positive effect on treating patients with Type 1 diabetes and DKD or in patients with CKD not due to diabetes. Clinicians should stay abreast of any new published studies in DKD with any of these class of agents.

\section{References}

1. Alicic RZ, Rooney MT, Tuttle KR (2017) Diabetic kidney disease - challenges, progress, and possibilities. Clin J Am Soc Nephrol 12: 2032-2045. Link: https://bit.ly/2Ad3s6g

2. Palsson R, Patel UD (2014) Cardiovascular complications of diabetic kidney disease. Adv Chronic Kidney Dis 21: 273-280. Link: https://bit.ly/3dGmlgv

3. Afkarian M, Sachs MC, Kestenbaum B, Hirsch IB, Tuttle KR, et al. (2013) Kidney disease and increased mortality risk in type 2 diabetes. J Am Soc Nephrol 24: 302-308. Link: https://bit.ly/2zqKF7e

4. United States Renal Data Sheet (2020) US Renal data system 2019 annual data report: epidemiology of kidney disease in the United States. Am J Kidney Dis 75: A6-A7. Link: https://bit.ly/35IFR9a

5. American Diabetes Association (2000) Diabetic nephropathy. Diabetes Care 23: S69-S72. Link:

6. Levin A, Tonelli M, Bonventre J, Coresh J, Donner J, et al. (2017) Global kidney health 2017 and beyond: a roadmap for closing gaps in care, research, and policy. Lancet 390: 1888-1917. Link: https://bit.ly/2LauMUU

7. Harashima S, Ogura M, Tanaka D, Fukushima T, Wang Y, et al. (2012) Sitagliptin add-on to low dosage sulphonylureas: efficacy and safety of combination therapy on glycaemic control and insulin secretion capacity in type 2 diabetes. Int J Clin Pract 66: 465-476. Link: https://bit.ly/3chYMKv

8. Sakata K, Hayakawa M, Yano Y, Tamaki N, Yokota N, et al. (2013) Efficacy of alogliptin, a dipeptidyl peptidase-4 inhibitor, on glucose parameters, the activigy of the advanced glycation end product (AGE) - receptor for AGE (RAGE) axis and albuminuria in Japanese type 2 diabetes. Diabetes Metab Res Rev 29: 624-630. Link: https://bit.ly/2xNdCJT

9. Groop P, Cooper M, Perkovic V, Emser A, Woerle J, et al. (2013) Linagliptin lowers albuminuria on top of recommended standard treatment in patients with type 2 diabetes and renal dysfunction. Diabetes Care 36: 3460-3468. Link: https://bit.ly/3bkmZhQ

10. Engel S, Suryawanshi S, Stevens SR, Josse RG, Cornel JH, et al. (2017) Safety of sitagliptin in patients with type 2 diabetes and chronic kidney disease: outcomes from TECOS. Diabetes Obes Metab 19: 1587-1593. Link: https://bit.ly/2WDGOXn

11. Mosenzon O, Leibowitz G, Bhatt DL, Cahn A, Hirshberg B, et al. (2017) Effect of saxagliptin on renal outcomes in the SAVOR-TIMI 53 trial. Diabetes Care 40: 69-76. Link: https://bit.ly/2ziJI05

12. White WB, Cannon CP, Heller SR, Nissen SE, Bergenstal RM, et al. (2013) Alogliptin after acute coronary syndrome in patients with type 2 diabetes. $\mathrm{N}$ Engl J Med 369: 1327-1335. Link: https://bit.ly/35Hubna

13. Rosenstock J, Perkovic V, Johansen O, Cooper M, Kahn S, et al. (2019) Effect of linagliptin vs placebo on major cardiovascular events in adults with type 2 diabetes and high cardiovascular and renal risk - The CARMELINA randomized clinical trial. JAMA 321: 69-79. Link: https://bit.ly/2WeVhPe

14. Mosenzon O, Blicher T, Rosenlund S, Eriksson J, Heller S, et al. (2019) Efficacy and safety of oral semaglutide in patients with type 2 diabetes and moderate renal impairment (PIONEER 5): a placebo-controlled, randomized, phase 3a trial. Lancet Diabetes Endocrinol 7: 515-527. Link: https://bit.ly/3fscXi9

15. Tuttle K, Lakshmanan M, Rayner B, Busch R, Zimmermann A, et al. (2018) Dulaglutide versus insulin glargine in patients with type 2 diabetes and moderate-to-severe chronic kidney disease (AWARD-7): a multicenter, open-label, randomized trial. Lancet Diabetes Endocrinol 6: 605-617. Link: https://bit.ly/2SQQkKr

16. Davies M, Bain S, Atkin S, Rossing P, Scott D, et al. (2016) Efficacy and safety of liraglutide versus placebo as ad-on to glucose-lowering therapy in patients with type 2 diabetes and moderate renal impairment (LIRA_RENAL): a randomized clinical trial. Diabetes Care 39: 222-230. Link: https://bit.ly/2LafzmT

17. Muskiet M, Tonneijck L, Huang Y, Liu M, Saremi A, et al. (2018) Lixisenatide and renal outcomes in patients with type 2 diabetes and acute coronary syndrome: an exploratory analysis of the ELIA randomized, placebo-controlled trial. Lancet Diabetes Endocrinol 6: 859-869. Link: https://bit.ly/2WhehwE

18. Mann JFE, Ørsted DD, Brown-Frandsen K, Marso SP, Poulter NR, et al. (2017) Liraglutide and renal outcomes in type 2 diabetes. N Engl J Med 377: 839-848. Link: https://bit.ly/3drU8K3

19. Marso SP, Bain SC, Consoli A, Eliaschewitz FG, Jódar E, et al. (2016) Semaglutide and cardiovascular outcomes in patients with type 2 diabetes. $N$ Engl J Med 375: 1834-1844. Link: https://bit.ly/2Lb93Mr

20. Gerstein HC, Colhoun HM, Dagenais GR, Diaz R, Lakshmanan M, et al. (2019) Dulaglutide and renal outcomes in type 2 diabetes: an exploratory analysis of the REWIND randomized, placebo-controlled trial. Lancet 394: 131-138. Link: https://bit.ly/2zp7Azs

21. Bethel MA, Mentz RJ, Merrill P, Buse JB, Chan JC, et al. (2020) Microvascula and cardiovascular outcomes according to renal function in patients treated with once-weekly exenatide: insights from the EXSCEL trial. Diabetes Care 43 446-452. Link: https://bit.ly/35JPVP5

22. Cherney D, Lund SS, Perkins BA, Groop PH5, Cooper ME, et al. (2016) The effect of sodium glucose cotransporter 2 inhibition with empagliflozin on microalbuminuria and macroalbuminuria in patients with type 2 diabetes. Diabetologia 59: 1860-1870. Link: https://bit.ly/2SPPihU

23. Cherney D, Heerspink H, Frederich R, Maldonado M, Pong A, et al. (2019) Twoyear effects of ertugliflozin on renal function. Presented at: American Diabetes Association 79th Scientific Sessions. San Francisco CA, Poster 1197.

24. Yale JF, Bakris G, Cariou B, Yue D, David-Neto E, et al. (2013) Efficacy and safety of canagliflozin in subjects with type 2 diabetes and chronic kidney disease. Diabetes Obes Metab 15: 463-473. Link: https://bit.ly/3bj1zBU

25. Fioretto P, Stefansson BV, Johnsson E, Cain VA, Sjostrom CD (2016) Dapagliflozin reduces albuminuria over 2 years in patients with type 2 diabetes mellitus and renal impairment. Diabetologia 59: 2036-2039. Link: https://bit.ly/2Lq5ySN

26. Wanner Ch, Inzucchi SE, Zinman B (2016) Empagliflozin and progression of kidney disease in type 2 diabetes. N Engl J Med 375: 1801-1802. Link: https://bit.ly/35KeTOl

27. Neal B, Perkovic V, Mahaffey K, de Zeeuw D, Fulcher g, et al. (2017) Canagliflozin and cardiovascular and renal events in type 2 diabetes. $\mathrm{N}$ Engl $\mathrm{J}$ Med 377: 644-657. Link: https://bit.ly/2WDGRax

28. Perkovic V, de Zeeuw D, Mahafffey K, Fulcher G, Erondu N, et al. (2018) Canagliflozin and renal outcomes in type 2 diabetes: results from the CANVAS Program randomised clinical trials. Lancet Diabetes Endocrinol 6: 691-704. Link: https://bit.ly/2WDKGwh

29. Mosenzon O, Wiviott SD, Cahn A, Rozenberg A, Yanuv I, et al. (2019) Effects of dapagliflozin on development and progression of kidney disease in patients with type 2 diabetes: an analysis from the DECLARE-TIMI 58 randomised trial. Lancet Diabetes Endocrinol 7: 606-617. Link: https://bit.ly/2YNUial

Citation: Irons BK, Minze M, Chastain L, McMurry ME (2020) Brief Review of Newer Antiglycemic Agents as Options in the Treatment of Diabetic Kidney Disease. Glob J Obes Diabetes Metab Syndr 7(2): 012-017. DOI: https://dx.doi.org/10.17352/2455-8583.000041 
30. Perkovic V, Jardine M, Bompoint S, Heerspink H, Charytan D, et al. (2019) Canagliflozin and renal outcomes in type 2 diabetes and nephropathy. $\mathrm{N}$ Engl J Med 380: 2295-2306. Link: https://bit.ly/3dx7Efg
31. Cherney DZ, Odutayo A, Aronson R, Ezekowitz J, Parker JD (2019) Sodium Glucose Cotransporter-2 inhibition and cardiorenal protection. J Am Coll Cardiol 74: 2511-2524. Link: https://bit.ly/3bgfiJH

Discover a bigger Impact and Visibility of your article publication with

\section{Peertechz Publications}

\section{Highlights}

* Signatory publisher of ORCID

* Signatory Publisher of DORA (San Francisco Declaration on Research Assessment)

* Articles archived in worlds' renowned service providers such as Portico, CNKI, AGRIS, TDNet, Base (Bielefeld University Library), CrossRef, Scilit, J-Gate etc.

- Journals indexed in ICMJE, SHERPA/ROMEO, Google Scholar etc.

* OAI-PMH (Open Archives Initiative Protocol for Metadata Harvesting)

* Dedicated Editorial Board for every journal

* Accurate and rapid peer-review process

* Increased citations of published articles through promotions

* Reduced timeline for article publication

Submit your articles and experience a new surge in publication services (https://www.peertechz.com/submission).

Peertechz journals wishes everlasting success in your every endeavours.

Copyright: () 2020 Irons BK, et al. This is an open-access article distributed under the terms of the Creative Commons Attribution License, which permits unrestricted use, distribution, and reproduction in any medium, provided the original author and source are credited.

Citation: Irons BK, Minze M, Chastain L, McMurry ME (2020) Brief Review of Newer Antiglycemic Agents as Options in the Treatment of Diabetic Kidney Disease. Glob J Obes Diabetes Metab Syndr 7(2): 012-017. DOI: https://dx.doi.org/10.17352/2455-8583.000041 